\section{How did retinoblastoma arise?}

SIR - We read with interest the article by Kyritsis et al. ${ }^{1}$, in which they suggest that retinoblastoma may have arisen from a primitive neuroectodermal cell. We have studied the properties of the glycolytic enzymes pyruvate kinase, hexokinase, aldolase and enolase in these tumours, and it is interesting to compare our data with the work of Kyritsis et al.

In normal fetal retina, five different forms of pyruvate kinase could be detected by electrophoresis $\left(K_{4}, K_{3} M, K_{2} M_{2}, K_{3}\right.$ and $\mathbf{M 4}^{2}$. In retinoblastoma, the $\mathbf{M}_{4}$ isozyme is completely absent, whereas in normal adult retina the $\mathrm{K}_{4}$ isozyme is almost completely absent. In normal retina, both fetal and adult, hexokinase type I predominated; retinoblastoma was characterized by the presence of hexokinase type II. The study of aldolase in retinoblastoma revealed a large predominance of the fetal type (for example A-type) in contrast with normal retina. Subsequent studies ${ }^{3}$ investigating the same enzymes in medulloblastoma and neuroblastoma gave support to the hypothesis that these tumours have a common embryonic origin with retinoblastoma. In a study of enolase 4 we found that neuroblastoma, medulloblastoma and retinoblastoma are characterized by the presence of all three types of enolase, namely $\alpha \alpha, \alpha \gamma$ and $\gamma \gamma$.

Thus we think that the results of Kyritsis et al. ${ }^{1}$ and our findings lead to the same conclusions.

\section{University Childrens and Clinical Genetics Centre} PO Box 18009, 3501 CA Utrecht, The Netherlands

C.W.M. VAN VEELEN* G.E.J. STAAL

* Department of Neurosurgery and †Department of Haematology, Academic Hospital, Utrecht, The Netherlands.

1. Kyritsis, A.P., Tsokos, M., Triche, T.J. \& Chader, G.J Nature 307, $471-473$ (1984).

2. Beemer, F.A., Vlug, A.M.C., Rijksen, G., Hamburg, A: \& Staal, G.E.J. Cancer Res, 42, 4228-4232 (1982).

3. Beemer, F.A. et al., Eur.J.Cancer clin.Oncol. 20, 253-259 (1984).

4. Beemer, F.A., Vlug, A.M.C., Van Veelen, C.W.M Rijksen, G. \& Staal, G.E.J. Cancer 54 , (in the press).

\section{Sex and generations of primroses}

SIR - The highly evolved heterostyle incompatibility system of primroses which, in most populations, ensures almost complete outcrossing, must surely be of sufficient importance to the primrose for it to have protected itself from an easy regress to an inbreeding species due to the rapid increase of homostyles, readily produced by mutation or, more probably, recombination. The controversy concerning the rate of self-fertilization of homostyle primroses, in which I was involved a generation ago and which is rekindled in the pages of your journal by Piper et al. (Nature 310, 50; 1984) and the News and Views item by Richards in the same issue (Nature 310, 12; 1984) is thus of some considerable importance for the sex life of the primrose. Richards castigates both myself and Crosby for a lack of good data while, at the same time, quoting both of our extensive population studies and my own careful investigations into homostyle protogyny in my first ever published paper (Heredity 12, $363 ; 1958)$. These and later studies clearly showed that the homostyle stigma was receptive to pollen well before anthers dehisced, and provided a likely explanation for a much greater frequency of outcrossing by homostyles than might otherwise be expected. Thus the observation of large amounts of homostyle pollen on homostyle stigmas is not, by any means, conclusive evidence for selffertilization. The earlier arriving thrum pollen may successfully compete with the later arriving homostyle pollen, as Richards indeed acknowledges.

I, too, have collected extensive data on seed counts per capsule and, using dominantly inherited flower colour markers had begun to obtain, in collaboration with Vivian Fyfe, direct estimates of the frequency of homostyle outcrossing. But I was diverted from these interests to other equally important areas of research. Indeed I had hoped that in the quieter years following my eventual retirement, perhaps a primrose generation or two in the future, these observations could have been extended and eventually published together with observations on the frequencies of homostyles in an ordinary population of primroses on the banks of Clare College, Cambridge, to which I had added a few homostyles in the late 1950 s. But now the present excitement has preempted these aspirations.

It was already clear from my own observations that the frequency of outcrossing might vary considerably according to the ecological conditions and, of course, also from year to year especially as a function of climate. Thus, observations in any one place or at any one time are clearly subject to considerable variation. In my extended discussion of this issue, including a comprehensive theoretical treatment (Phil. Trans. $R$. Soc. B242, 517-549; 1960), I pointed out, following Mather and others, that the gradual evolution of an incompatibility system would be likely to have led to some form of partial self-incompatibility before the final evolution of the incompatibility switch mechanism itself had been perfected. This would account, for example, for the protogynous phase observed in the homostyles, that itself could account for the tendency of the homostyles to cross-fertilize more than expected. The crucial question is, what limits the increase in frequency of homostyles in most populations in which they arise? (In collaboration with E.B. Ford, it was clearly shown that predominantly pinthrum populations did contain rare homostyles.) Crosby assumed that, given their enormous advantage due to selffertilization, especially if this was complete or almost so, it must be viability disadvantage that limits their increase. The theory, however, demands extraordinarily low viabilities which appear to be inconsistent with the observed ratios from breeding experiments. On the other hand, it can be shown that a reasonable degree of cross-fertilization by the homostyles can prevent their increase, given only a moderate viability disadvantage. This result, to my mind, was compatible with the overall data and provided a simple explanation for the protection of the heterostyle outcrossing system against invasion by variant inbreeding homostyles.

The perturbation theory used to analyse the complex population genetic models underlying this system clearly foreshadowed subsequent analyses of "protected' equilibria and 'evolutionarily stable strategies' by John Maynard Smith and others. Furthermore the paper in Phil. Trans., together with an accompanying paper by Crosby, were heralded in the pages of your journal as being amongst the first applications of computers to genetics and, more specifically, to the analysis of complex population genetic models. So, whatever the rights and wrongs of the theory and data, the problem stimulated new approaches to the analysis of complex evolutionary systems. Computer applications have clearly advanced more quickly in the last quarter of a century than work on the sex life of the primrose. Hopefully, another generation will be enough to give rise to a convincing and conclusive answer to the important question, for the primrose, as to what limits the increase in frequency of homostyles.

WALTER F. BODMER

Imperial Cancer Research Fund,

Lincoln's Inn Fields,

London WC2A 3PX, UK

\section{A weighty problem cracked}

SIR - I am writing to tell you about a discovery which seems far-reaching in its implications, and could well throw light on a number of outstanding problems in physics, such as why dropped toast always falls marmalade-down.

I must make it clear that I am not a physicist in the generally accepted sense of the word. To be honest, I am not a physicist in any sense of the word. Anyway, here we go.

It all started when I had a slight accident. I fell over in the saloon bar at the Grovelling Toad and struck the back of my head on the space invaders machine. After two or three more pints I was back to normal, except for a severe pain in the neck which I could only relieve by crouching down and 